\title{
Dynamics of Earthquake Faulting in Subduction Zones: Inference from Pseudotachylytes and Ultracataclasites in an Ancient Accretionary Complex
}

by Kohtaro Ujiie

doi:10.2204/iodp.sd.s01.21.2007

The fault rocks in ancient accretionary complexes exhumed from seismogenic depths may provide an invaluable opportunity to examine the mechanisms and mechanics of seismic slip in subduction thrusts and splay faults. In order to understand the dynamics of earthquake faulting in subduction zones, we analyzed pseudotachylytes and ultracataclasites from the Shimanto accretionary complex in southwest Japan.

\section{Pseudotachylytes}

The following conclusions were derived from the analysis of pseudotachylytes (Ujiie et al., 2007a):

1. At seismogenic depths in the subduction zone, a cataclastic thrust zone develops at the top of the mélange, and the coseismic slip is concentrated into a narrow zone less than a few millimeters thick.

2. The pseudotachylyte displays a fragment-laden, glasssupported texture resulting from rapid cooling of the frictional melt (Fig. 1), which is consistent with a very short cooling time of the melt layer calculated using thermal modeling. The rapid cooling of the melt layer is due to its narrow thickness, resulting in the fast healing of the coseismic slip zone by the solidified melt layer.

3. The pseudotachylyte is derived from the frictional melting of an illite-rich ultracataclasite layer. The variation in the volume fraction of unmelted grains in the pseudotachylyte matrix primarily represents the difference in the initial volume fraction of illite in the ultracataclasite layer prior to frictional melting. The minimum melting temperature is $1100^{\circ} \mathrm{C}$, which is $\sim 850-920^{\circ} \mathrm{C}$ greater than the maximum temperatures recorded in the host rocks.

4. The viscosity and shear resistance of the melt layer are very low (Fig. 2); therefore, the dynamic weakness of the fault, acceleration of seismic slip, and propagation of instability can possibly occur during an earthquake. This would contribute, at least locally, to the efficiency with which stored strain energy is released and, hence, to the earthquake magnitude in subduction zones.

5. Such frictional melting of the illite-rich slip zone may be applicable to subduction thrusts and faults in other accretionary complexes. The melting of the illite-rich slip zone is likely to form a hydrous melt layer, possibly leading to a high water content in these pseudotachylytes.

\section{Ultracataclasites}

The new observations of ultracataclasites within the subduction thrust and their possible relevance to the dynamic slip processes are summarized below (Ujiie et al., 2007b).

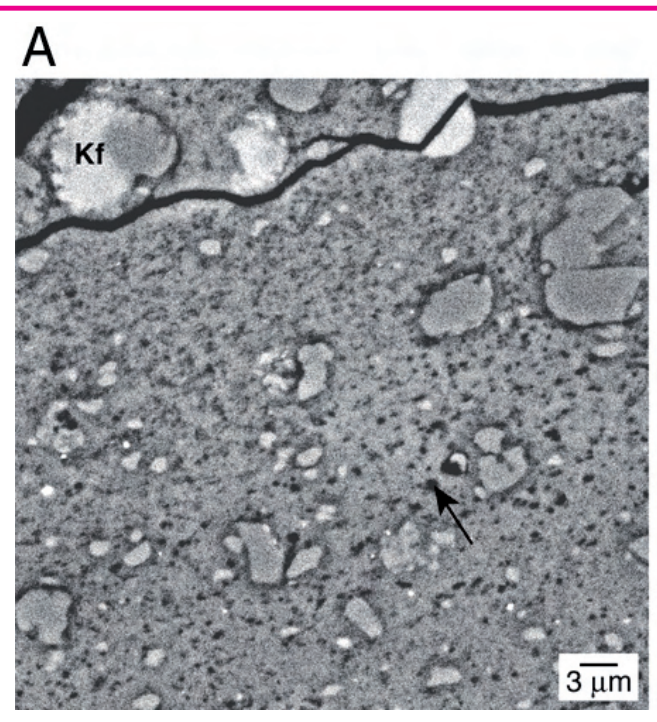

$\mathrm{B}$

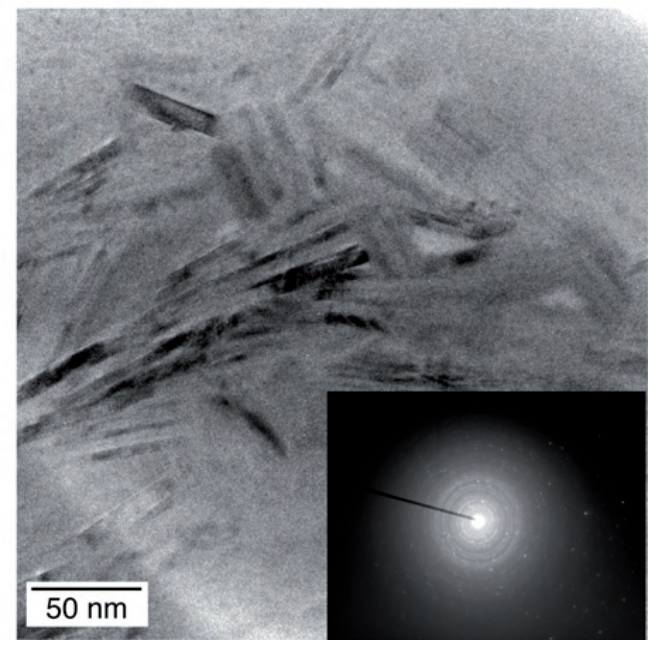

Figure 1. Evidence of frictional melting recorded in the pseudotachylytes. [A] Backscattered electron image of the pseudotachylyte, characterized by vesicles (black arrow) and embayed grains in the homogeneous matrix. Kf: K-feldspar. [B] Transmission electron micrograph of pseudotachylyte (bright-field image). Note the presence of euhedral microcrystals in a glassy matrix. Inset shows the diffraction pattern of the microcrystals.
The thrust faults in the Shimanto accretionary complex of southwest Japan imbricate the mélange derived from sedimentary rocks and basalt, which represent a duplex underplating associated with the downward step of the subduction thrustatseismogenic depths $(4-6 \mathrm{~km}$ deep, $\left.130-150^{\circ} \mathrm{C}\right)$. One well exposed duplex-fault zone consists mainly of foliated cataclasites and ultracataclasites derived from basalt. The fault zone structure suggests slip localization along the 2-20-cm-thick ultracataclasite layer at the 


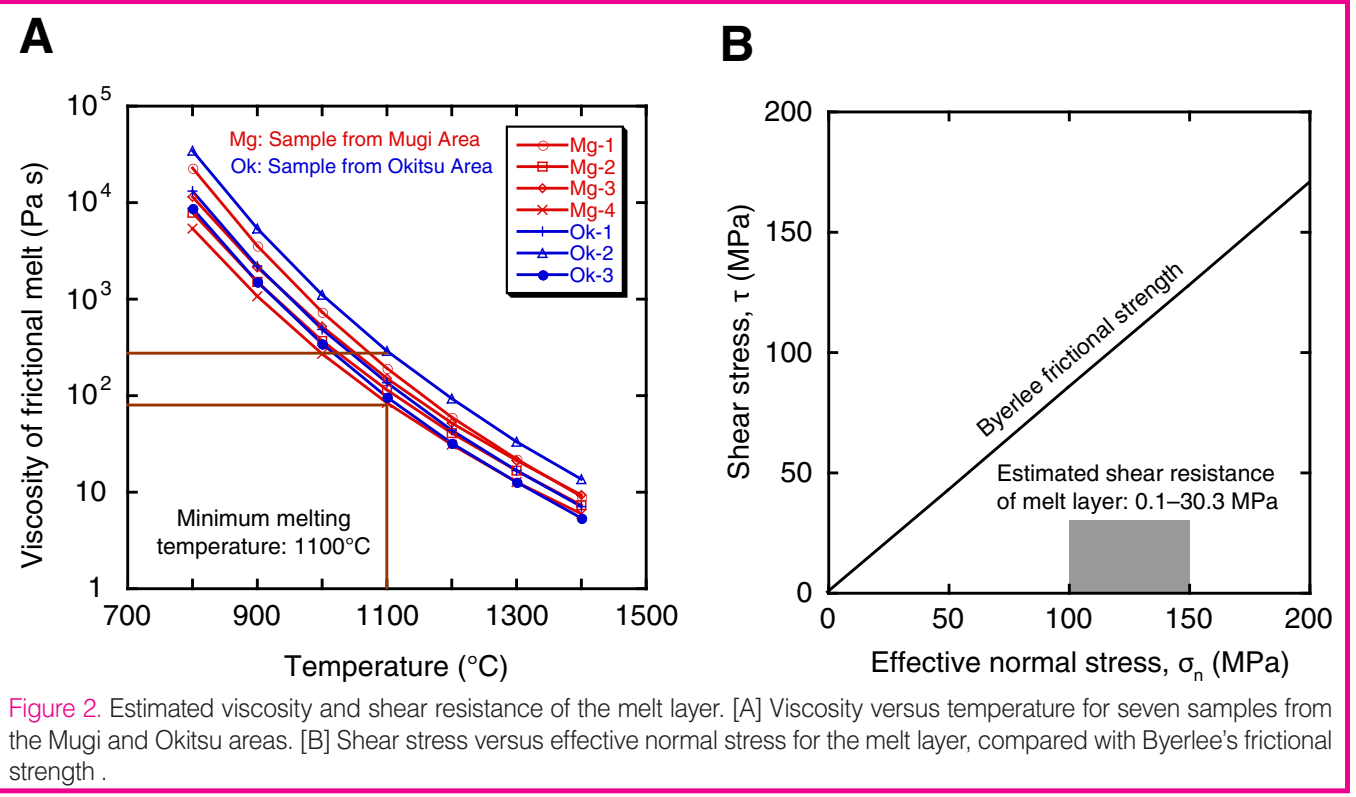

boundary between different lithologies. The ultracataclasite layer is marked by fluid-related processes, as shown by the alteration along the ultracataclasite and the concentration of veins near the ultracataclasite. New observations of the ultracataclasite layer have revealed that fluidization could occur during the localized slip.
Fluidization is suggested by the injections of granular material into the mélange without the sorting of finely-grained particles, and by the quantitative data that few particles in the injected material have fragmented counterparts (Fig. 3). The fluidization during localized slip under fluid-infiltrated conditions is likely due to thermal pressurization, and injection structures may represent hydraulic fracturing normal to the least principal stress.

\section{References}

Ujiie, K., Yamaguchi, H., Sakaguchi, A., and Toh, S., 2007a. Pseudotachylytes in an ancient accretionary complex and implications for melt lubrication during subduction zone earthquakes. J. Struct. Geol., 29:599-613, doi:10.1016/j. jsg.2006.10.012.

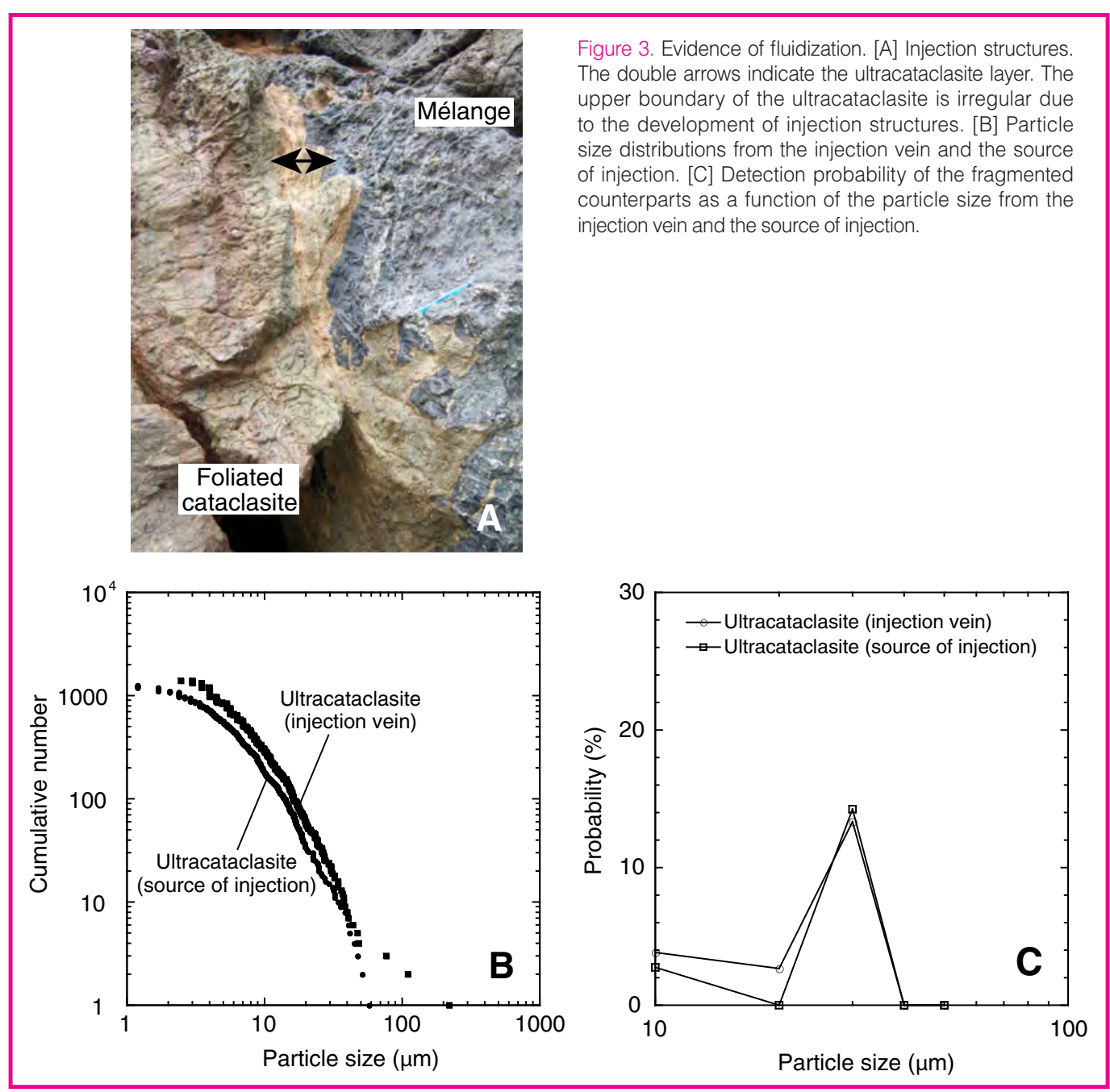

Ujiie, K., Yamaguchi, A., Kimura, G., and Toh, S., 2007b. Fluidization of granular material in a subduction thrust at seismogenic depths. Earth Planet. Sci. Lett., 259:307-318, doi:10.1016/j.epsl.2007.04.049.

\section{Author}

Kohtaro Ujiie, Institute for Research on Earth Evolution (IFREE), Japan Agency for Marine-Earth Science and Technology (JAMSTEC), 3173-25 Showa-machi, Yokohamacity, Kanagawa 236-0001, Japan, e-mail: ujiiek@ jamstec.go.jp. 